Oikos 120: 1897-1908, 2011

doi: $10.1111 / j .1600-0706.2011 .19465 . x$

(C) 2011 The Authors. Oikos (C) 2011 Nordic Society Oikos

Subject Editor: Daniel Gruner. Accepted 25 March 2011

\title{
Ecological factors associated with the strength of trophic cascades in streams
}

\author{
Carolyn M. Kurle and Bradley J. Cardinale \\ C. M. Kurle(ckurle@ucsd.edu), Div. of Biological Sciences, Univ. of California San Diego, 9500 Gilman Drive, No. 0116, La Jolla, CA \\ 92093-0116, USA. - B. J. Cardinale, School of Natural Resources and Environment, Univ. of Michigan, Ann Arbor, MI 48109-1041, USA.
}

\begin{abstract}
Trophic cascades are extensively documented in nature, but they are also known to vary widely in strength and frequency across ecosystems. Therefore, much effort has gone into understanding which ecological factors generate variation in cascade strength. To identify which factors covary with the strength of cascades in streams, we performed a concurrent experiment across 17 streams throughout the Sierra Nevada Mountains. We eliminated top consumers from experimental substrates using electrical exclusions and compared the strength of indirect effects of consumers on the biomass of primary producers relative to control patches. In each stream we 1) classified the dominant invertebrate herbivores according to lifehistory traits that influence their susceptibility to predators, 2) determined the abundance and diversity of algae and herbivores, and 3) measured production-to-biomass ratios (P:B) of the stream biofilm. This allowed us to assess three common predictions about factors thought to influence the strength of trophic cascades: cascade strength 1) is weaker in systems dominated by herbivores with greater ability to evade or defend against predators, 2 ) is stronger in systems characterized by low species diversity, and 3) increases with increasing producer P:B.

When averaged across all streams, the indirect effect of predators increased the biomass of periphyton by a mean $60 \%$. However, impacts of predators on algae varied widely, ranging from effects that exacerbated algal loss to herbivores, to strong cascades that increased algal biomass by 4.35 times. Cascade strength was not related to herbivore traits or species diversity, but decreased significantly with increasing algal diversity and biofilm P:B in a stream. Partial regression analyses suggested that the relationship between cascade strength and algal diversity was spurious, and that the only significant covariate after statistically controlling for cross-correlations was algal P:B. Our study contributes to the ongoing debate about why trophic cascade strength varies in nature and is useful because it eliminates factors that have no potential to explain variation in cascades within these stream ecosystems.
\end{abstract}

Hairston et al. (1960) proposed that plant biomass on the planet is indirectly maintained by predators that control the abundance of herbivores, and therefore, the amount of plant tissue eaten. Ever since the publication of this seminal paper, ecologists have worked to test this hypothesis and quantify how impacts of predators cascade through food webs to indirectly control the abundance and biomass of primary production. After several decades of research, we now know that the presence or absence of trophic cascades can profoundly impact community structure and primary production at the base of a food web (Estes and Palmisano 1974, Paine 1980, Carpenter et al. 1985, Kurle et al. 2008). But the ecological role of predators in controlling plant biomass has proven to be highly variable, both within and among ecosystems. As such, there is now much interest in understanding which ecological factors mediate variation in the strength of trophic cascades (Brett and Goldman 1996, Pace et al. 1999, Polis 1999, Polis et al. 2000, Power 2000, Schmitz et al. 2000, Halaj and Wise 2001, Shurin et al. 2002, 2006, Borer et al. 2005, Mooney et al. 2010).
Researchers have identified a number of potential factors that might control the strength of trophic cascades. Here we focus on three, non-mutually exclusive variables that have been widely discussed as potentially controlling the strength of trophic cascades among systems: 1) behavioral avoidance of predation by herbivores, 2) community diversity, and 3) the production-to-biomass ratio (P:B) of primary producers (Strong 1992, Schmitz et al. 2004, Shurin and Seabloom 2005). First, it has been argued that trophic cascade strength is a function of herbivore behaviors or traits that minimize interactions with their predators, thereby allowing them to avoid predation (Persson 1999, Schmitz et al. 2004). A three trophic level cascade can be dampened if herbivores escape predation via a behavioral or defensive trait and then return to continue grazing. Herbivore mobility and defense (e.g. shells) are two such traits that could lead to increased herbivore escape, turnover, and/or replacement, and a subsequent dampening of trophic cascade strength. A prediction that follows is that systems dominated by highly mobile or 
defended herbivores that can escape predation and continue grazing exhibit weaker trophic cascades (Fig. 1A).

Second, in his classic critique of the literature on trophic cascades, Strong (1992) argued that cascades are likely to be strongest in simple, linear food chains and weaker in more diverse, reticulate food webs. His argument was based on the assumption that more complex food webs have a higher degree of producer and consumer redundancy. In other words, an alternate conspecific is always ready to replace those that are consumed or otherwise deterred from grazing. Others have built on this argument by suggesting that the strength of trophic cascades is inversely proportional to the magnitude of compensatory responses whereby surviving resource species compensate for the consumer-induced reduction of other resource species (Polis and Strong 1996, Polis 1999, Schmitz et al. 2000, Halaj and Wise 2001, Duffy et al. 2007, O'Gorman and Emmerson 2009) (Fig. 1B).

Lastly, it has been proposed that the strength of trophic cascades increases with increasing plant production-tobiomass ratios $(\mathrm{P}: \mathrm{B})$ or system productivity (Shurin and Seabloom 2005). According to this hypothesis, plants that allocate more resources to growth and photosynthetic tissue per unit biomass (and thus have higher $\mathrm{P}: \mathrm{B}$ ratios) also produce more edible structures that are nutritious to herbivores. The higher nutritional quality of primary production translates into greater palatability for, and ultimately higher numbers of, herbivores. This paradigm assumes that more energy is then available for predators, thereby increasing predator numbers and strengthening top-down control (Cyr and Pace 1993, Cebrian and Duarte 1994, Duarte and Cebrian 1996, Shurin and Seabloom 2005, Cebrian et al. 2010) (Fig. 1C).

A number of individual experiments have demonstrated the potential for herbivore life-history traits (McIntosh and Townsend 1996, Bernot and Turner 2001), species diversity (Gruner 2004, O'Gorman et al. 2008), and ecosystem productivity (Wootton and Power 1993, Fraser and Grime 1998) to moderate the strength of trophic cascades in individual ecosystems. In addition, several meta-analyses have asked which, if any, of these factors co-vary with the strength of trophic cascades across different ecosystems (Halaj and Wise
2001, Schmitz et al. 2004, Borer et al. 2005). Unfortunately, the conclusions of these studies and analyses have seldom agreed. In part, this may be due to the fact that individual experiments and meta-analyses lie at opposite extremes of a research continuum: the former sacrifices scope in order to better understand why cascades operate in a single system, whereas the latter seeks generality by looking for covariates of trophic cascades across systems and experiments that are, quite often, not directly comparable. As such, it is perhaps not surprising that conclusions from individual experiments often differ from the generalizations of meta-analyses (compare Borer et al. 2005, Gruner 2004), and that meta-analyses which have focused on differing subsets of the literature have come to divergent conclusions (compare Borer et al. 2005, Edwards et al. 2010).

Given the inconsistency of results, researchers have begun to use comparative approaches that integrate the strengths of both individual experiments and meta-analyses (Tessier and Woodruff 2002, Power et al. 2008). Here we take a similar approach to try and gain some insight into the factors that potentially control trophic cascades in streams. We performed an experiment concurrently in 17 different stream ecosystems, using identical methods to eliminate top consumers (trout) and measure the strength of subsequent indirect effects on the biomass of primary producers (periphyton). Streams are an opportune system for this type of comparative work since past experiments examining fish, invertebrates, and periphyton in streams have demonstrated interactions that range from trophic 'trickles' (Townsend 2003) to strong behaviorally or density mediated cascades (Power 1990,1992, Townsend 2003). Wide variation in the strength of cascades is an ideal situation for identifying covarying factors such as the life-history traits of herbivores, diversity, and plant $\mathrm{P}: \mathrm{B}$ ratios (turnover rate). Our use of comparative experiments complements other forms of study on trophic cascades in the sense that, like meta-analyses, we generalize the effect size of higher consumers across multiple study units in order to identify possible sources of variation. Yet, by using identical methodology in systems that have similar organisms and trophic structures, the list of possible covariates that need be considered is greatly reduced.
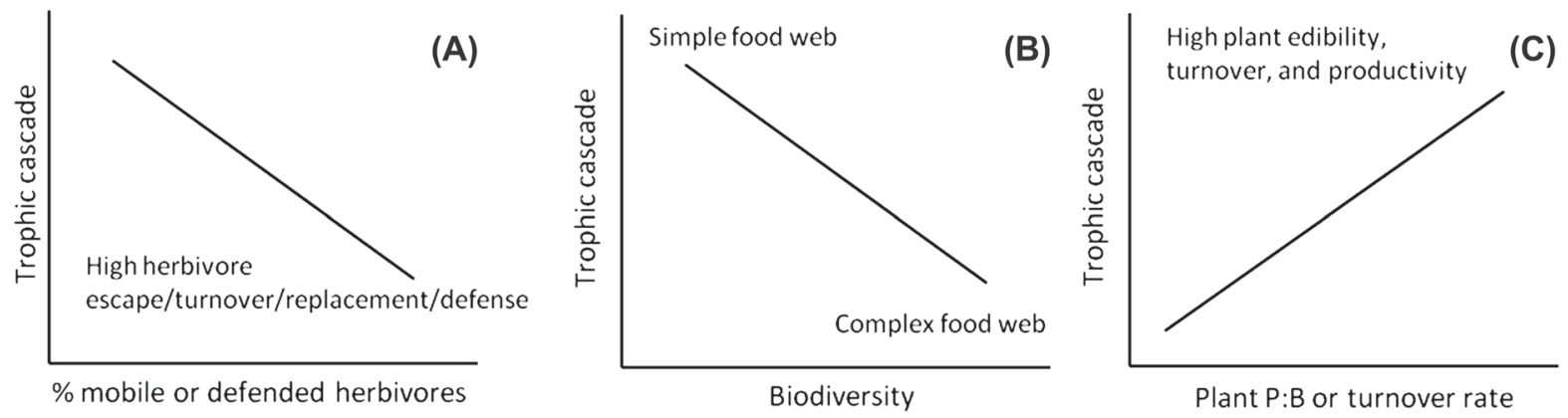

Figure 1. (A) Prediction 1 argues that trophic cascades (TCs) are weaker in systems where the dominant herbivores are able to avoid predation through increased mobility or defensive structures (Persson 1999, Schmitz et al. 2004). (B) Prediction 2 argues that TCs are weaker in more diverse/complex food webs (Strong 1992) because higher producer and/or herbivore diversity creates alternate pathways for energy flow to top consumers and also allows for compensatory responses whereby surviving resource species compensate for the consumerinduced reduction of species. (C) Prediction 3 states that the strength of trophic cascades increases as the producer production-to-biomass (P:B) ratios increase (Shurin and Seabloom 2005). This prediction is predicated on the assumption that producers with higher P:B ratios have more edible structures and faster turnover, thereby supporting higher densities of herbivores, and thus predators, leading to greater top-down control. 


\section{Methods}

\section{Study streams}

Our experiments were performed in the summer of 2007 in 17 streams in the Mono Lake and Owens River basins in the eastern Sierra Nevada mountain range near the Univ. of California's Sierra Nevada Aquatic Research Laboratory (Fig. 2A). In choosing sites for our experiments, our goal was to maximize variation in the composition, diversity, and productivity of stream food webs while still choosing sites with similar trophic structures (streams with only three trophic levels: algae, invertebrate grazers and trout). To accomplish this, we used prior surveys of algae, invertebrates, and fish throughout the region (Blinn and Herbst 2003, Herbst and Blinn 2007) to identify a set of sites that exhibited maximal variation in algal diversity and biomass, herbivore diversity, and nutrient levels, but where all sites had trout as the top consumer (California Dept of Fish and Game records were used to identify streams dominated by either Oncorhynchus mykiss or Salmo trutta). From this list we were forced to eliminate a set of sites that were known to be frequented by hikers and anglers, as well as sites where land access or permitting were prohibitive. The remaining 17 streams represented secure and/or remote locations in which we could set up experiments that would run undisturbed during the three month period of the project.

\section{Experimental treatments}

To quantify the strength of trophic cascades in each stream, we placed three unglazed ceramic tiles $(15 \times 15 \mathrm{~cm})$ flush with the natural substrates in stream riffles, and used these as standardized substrates for colonization by periphyton and invertebrates. Although these tile substrates may appear small to a human observer, it should be noted that the experimental units were sufficiently large to contain final population sizes of algae that averaged $1.9 \times 10^{5}$ algal cells per $\mathrm{cm}^{2}$ of tile area.

We used an electrical exclusion technique that has been widely employed by stream ecologists (Opsahl et al. 2003, Pringle and Hamazaki 1997) to vary the number of trophic levels with access to the algal colonization substrates. Electrical 'fences' made of 17 -gauge copper wires were affixed with Z-Spar underwater epoxy to the surface of each tile and connected to a solar powered fence charger that emitted a oneamp pulse s ${ }^{-1}$ (Fig. 2B). Because sensitivity to electrical shock is inversely proportional to body size (Dalziel and Massoglia 1956), we were able to establish voltages that would exclude all fish having body lengths greater than $5 \mathrm{~cm}$ (500 volts), or to exclude fish and herbivores averaging greater than $5 \mathrm{~mm}$ (1800 volts). In contrast to their impact on invertebrates and fish, prior work has shown that these electrical exclusions are not sufficiently powerful to alter the growth or colonization of algae (Pringle and Blake 1994).

One of the three tiles in each stream was randomly assigned to serve as a control unit and contained the copper wire 'fence,' but was not hooked to the solar fence charger. This tile was colonized by periphyton and accessible to invertebrate grazers and predatory fish. The remaining two tiles in each stream were randomly assigned to the low voltage treatment from which predatory fish were excluded (leaving algae and herbivores) or the high voltage treatments on which fish and invertebrate herbivores were excluded (leaving algae only). We did not observe invertebrate predators on the tiles during any measurements taken in this experiment (which has the potential to create four functional trophic levels or intraguild effects); therefore, we have simplified the presentation of results by classifying tiles within a stream as having one (algae only), two (algae + invertebrate herbivores) or three (algae + invertebrate herbivores + predatory trout) trophic levels (TL). Tiles were incubated for 60 days allowing for roughly 15-20 generations of algal growth.

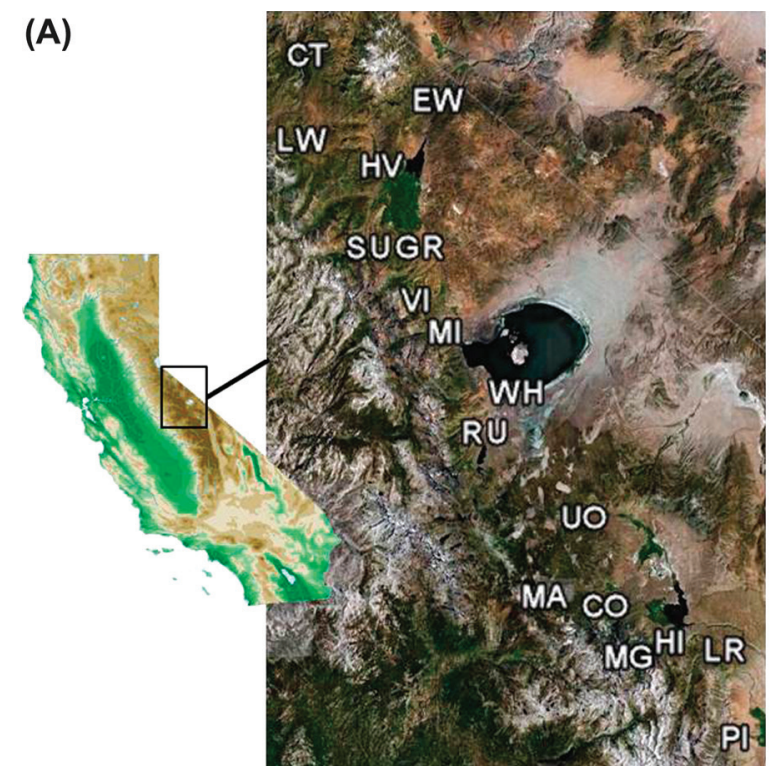

(B)

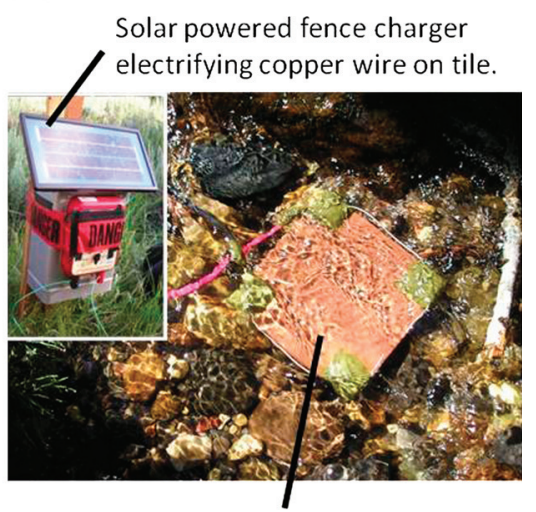

Experimental tile with copper wire electrified 'fence' around perimeter.

Figure 2. (A) Location of the stream study sites in the Sierra Nevada mountain range of California (see Table 1 for stream abbreviations and latitude and longitude locations for each stream). (B) We excluded predatory fish and herbivores from tiles placed within the streams using electrified fences made of copper wire and attached to solar powered fence chargers where capacitors were used to vary voltages between 500 and 1800 volts. 
Table 1. Names, abbreviations, and locations (latitude and longitude) of study streams, abundances of herbivores with predator avoidance strategies (\% mobile and \% defended herbivores per stream), the numbers of herbivore and algal species present in each stream, the production-to-biomass ratio (P:B) for algae at carrying capacity on one trophic level tiles, and the metric used to indicate the strength of a trophic cascade $(\mathrm{TC})$ within a stream $(\ln [P+/ P-]$, where $\mathrm{P}+$ and $\mathrm{P}-$ are algal biomass (measured as chlorophyll a) on experimental tiles in the presence verses absence of fish predators, respectively).

\begin{tabular}{|c|c|c|c|c|c|c|c|c|c|}
\hline Stream & Code & Latitude & Longitude & $\%$ mobility & $\%$ defended & $\begin{array}{l}\text { No. herbivore } \\
\text { species }\end{array}$ & $\begin{array}{l}\text { No. algal } \\
\text { species }\end{array}$ & $P: B$ & TC metric \\
\hline Convict & $\mathrm{CO}$ & $37^{\circ} 36^{\prime} 52^{\prime \prime}$ & $118^{\circ} 49^{\prime} 55^{\prime \prime}$ & 60.4 & 2.6 & 7 & 52 & 0.008 & -0.1876 \\
\hline Cottonwood & CT & $38^{\circ} 27^{\prime} 03^{\prime \prime}$ & $119^{\circ} 26^{\prime} 15^{\prime \prime}$ & 63.2 & 1.2 & 11 & 44 & 0.004 & 0.6444 \\
\hline E. Walker & EW & $38^{\circ} 22^{\prime} 53^{\prime \prime}$ & $119^{\circ} 11^{\prime} 13^{\prime \prime}$ & 49.9 & 1.4 & 8 & 67 & 0.023 & 0.3860 \\
\hline Green & GR & $38^{\circ} 09^{\prime} 33^{\prime \prime}$ & $119^{\circ} 13^{\prime} 24^{\prime \prime}$ & 66.0 & 8.7 & 7 & 59 & 0.004 & 0.6868 \\
\hline Harvey & HV & $38^{\circ} 16^{\prime} 57^{\prime \prime}$ & $119^{\circ} 17^{\prime} 56^{\prime \prime}$ & 24.0 & 0.6 & 7 & 72 & 0.012 & 0.3990 \\
\hline Hilton & $\mathrm{HI}$ & $37^{\circ} 33^{\prime} 33^{\prime \prime}$ & $118^{\circ} 45^{\prime} 20^{\prime \prime}$ & 99.1 & 0.0 & 4 & 53 & 0.016 & -0.2821 \\
\hline Little Walker & LW & $37^{\circ} 32^{\prime} 45^{\prime \prime}$ & $119^{\circ} 26^{\prime} 59^{\prime \prime}$ & 58.8 & 0.0 & 9 & 64 & 0.010 & 0.5725 \\
\hline Lower Rock & LR & $37^{\circ} 32^{\prime} 45^{\prime \prime}$ & $118^{\circ} 38^{\prime} 60^{\prime \prime}$ & 33.0 & 0.0 & 4 & 40 & 0.002 & 0.9472 \\
\hline Mammoth & MA & $37^{\circ} 37^{\prime} 51^{\prime \prime}$ & $118^{\circ} 59^{\prime} 45^{\prime \prime}$ & 66.8 & 0.3 & 8 & 62 & 0.012 & 0.1648 \\
\hline McGee & MG & $37^{\circ} 34^{\prime} 07^{\prime \prime}$ & $118^{\circ} 47^{\prime} 00^{\prime \prime}$ & 97.4 & 0.0 & 5 & 46 & 0.009 & 0.0182 \\
\hline Mill & MI & $38^{\circ} 01^{\prime} 52^{\prime \prime}$ & $119^{\circ} 10^{\prime} 40^{\prime \prime}$ & 81.1 & 0.0 & 5 & 44 & 0.003 & 1.4651 \\
\hline Pine & PI & $37^{\circ} 24^{\prime} 46^{\prime \prime}$ & $118^{\circ} 38^{\prime} 01^{\prime \prime}$ & 50.5 & 4.3 & 4 & 36 & NA & 0.8259 \\
\hline Rush & RU & $37^{\circ} 52^{\prime} 44^{\prime \prime}$ & $119^{\circ} 06^{\prime} 19^{\prime \prime}$ & 11.4 & 56.3 & 7 & 45 & 0.043 & -0.1299 \\
\hline Summers & SU & $38^{\circ} 21^{\prime} 07^{\prime \prime}$ & $119^{\circ} 16^{\prime} 50^{\prime \prime}$ & 28.2 & 6.7 & 10 & 79 & 0.037 & -0.2625 \\
\hline Upper Owens & UO & $37^{\circ} 44^{\prime} 56^{\prime \prime}$ & $118^{\circ} 54^{\prime} 59^{\prime \prime}$ & 24.0 & 34.0 & 9 & 61 & 0.012 & 0.2768 \\
\hline Virginia & VI & $38^{\circ} 04^{\prime} 45^{\prime \prime}$ & $119^{\circ} 12^{\prime} 11^{\prime \prime}$ & 55.8 & 1.6 & 10 & 39 & 0.006 & 0.5785 \\
\hline Walker Highway & $\mathrm{WH}$ & $37^{\circ} 54^{\prime} 30^{\prime \prime}$ & $119^{\circ} 05^{\prime} 42^{\prime \prime}$ & 12.3 & 8.2 & 6 & 69 & 0.049 & -0.3964 \\
\hline
\end{tabular}

Now that we have described the key features of our study, we would like to take a moment to point out the strengths and weaknesses of our study design. We intentionally designed our study to test hypotheses using a regressionbased approach in which each stream contributed just one observation to the entire dataset and treatments were not replicated in any given stream. Regression-based approaches with fewer replicates and more treatments along an $\mathrm{x}$-axis are generally among the most powerful for detecting relationships among two or more variables and for generating quantitative estimates of covariance (Cottingham et al. 2005). Because there were practical limitations to the number of exclosures we could set up and manage, we felt it was more powerful to add more streams to the dataset than to replicate treatments within streams. However, this design also has obvious limitations. For example, without replication of treatments in individual streams, we cannot say anything about the significance of indirect effects of fish predators on algae in any single stream ecosystem. Furthermore, including just one replicate per stream increases the chance of getting an erroneous measure of cascade strength (i.e. obtaining an estimate that is not truly representative of the mean value for that system). Presumably, erroneous data points become statistically irrelevant as the number of streams included in the dataset increase. But because our dataset contains just 17 streams total, readers should consider this caveat whenever we report non-significant results.

\section{Measured variables}

To measure the effectiveness of the electrical exclusions, we quantified herbivore densities on each tile at weekly intervals by counting individuals with the aid of a glass bottom viewing bucket. This method allowed us to identify most invertebrates to the level of family, and sometimes to genus, which was sufficient to differentiate grazing invertebrates from other functional groups. We quantified the frequency with which fish visited each tile substrate, as well as the duration of time each fish spent foraging on invertebrates during each visit. Fish visits were determined by visual observations conducted for a total of four hours at each stream (split equally between dawn, 5:30-7:30 a.m., and dusk, 6:00-8:00 p.m.). An observer watched tiles from the stream bank for a total of two hours in the morning, and two hours in the evening on a single day. Using binoculars, the observer counted the number of fish visiting the tiles over these two hour periods, binning the number of fish visits at five minute intervals. The duration of each fish visiting a tile during these observation periods was then timed using a stop-watch. While this method allowed us to determine the effectiveness of fish exclusions, it did not allow us to distinguish which of the two trout species visited the tiles.

At the end of the 60 day study period, each tile was pulled from the stream and all sessile invertebrates were removed and preserved in $90 \% \mathrm{EtOH}$ for later identification and enumeration. Tiles were then placed individually in 2.71 airtight metabolism chambers which were filled with stream water filtered through a 1-um mesh. Initial dissolved oxygen (DO) in each chamber was measured using an $\mathrm{O}_{2}$ probe. Air bubbles were then removed from the chambers with a syringe, and the chambers were sealed, covered with a tarp to eliminate light, and incubated in situ at ambient stream temperature for $1.3 \pm$ SD $0.1 \mathrm{~h}$. After incubation, DO was measured a second time and the change in oxygen concentration was used to calculate rates of dark respiration (R). Chambers were then sealed and incubated a second time in the light for $0.7 \pm$ SD $0.3 \mathrm{~h}$. The change in DO over the light interval was used to calculate net primary production (NP). Gross primary production (GPP; $\mathrm{mg} \mathrm{O}_{2} \mathrm{~cm}^{-2} \mathrm{~h}^{-1}$ ) was then calculated as R+ NP. We have used these methods to successfully measure metabolism of stream periphyton in numerous other studies (Cardinale et al. 2002, 2009).

Following measurements of GPP, algae were scraped from the tiles, rinsed into a tray, brought to a constant volume, and homogenized with a hand-blender. One sub-sample of algae from each tile was filtered onto a 25 -mm GFF filter 
which was placed into a $15-\mathrm{ml}$ Falcon tube containing $10 \mathrm{ml}$ of $90 \% \mathrm{EtOH}$. Tubes were covered with aluminum foil and transported to the lab on ice where they were kept dark and in a freezer until later analysis of chlorophyll a $\left(\mathrm{mg} \mathrm{l}^{-1}\right)$ via spectrophotometry to estimate algal biomass (Steinman and Lamberti 1996). Biomass specific rates of production (plant productivity-to-biomass ratios (P:B)) were calculated for all streams (except one due to missing data) by dividing GPP by values of chlorophyll a measured on tiles with predators and herbivores excluded (1 TL) (Shurin and Seabloom 2005).

At the end of the experiment we further determined the abundance, composition, and species richness of algae and herbivores on natural substrates in each stream to assess the pool of species that was available to colonize the tile substrates. To estimate algal diversity on hard substrates found in riffle habitats, we used a toothbrush to remove algae from $15.9 \mathrm{~cm}^{2}$ sections on 10 median-sized rocks collected at evenly spaced intervals along transects placed in two riffles in each stream reach. These samples were pooled into a composite and preserved in 3\% formalin for later counting and identification of algal species. The density of all Bacillariophyceae, Cyanobacteria, Chlorophyceae, Euglenophyceae and Pyrrophyta were determined from material allowed to settle in a Utermöhl chamber (Utermöhl 1958). A minimum of 400 units (individuals, colonies or filaments) were identified from randomly selected transects at $480 \times$ magnification. Diatom frustules were then cleaned via boiling in 30\% hydrogen peroxide, mounted in Hyrax, and identified at $1500 \times$. Herbivores were collected from three Surber samples $(0.25 \times 0.25 \mathrm{~m})$ taken in each of two riffles immediately upstream of our experimental site. All herbivores were preserved in $90 \% \mathrm{EtOH}$, identified to the lowest possible taxa (usually genus), and enumerated later in the laboratory.

\section{Statistical analysis}

To assess how well the electrical exclusions impacted fish foraging on the tiles, we used analyses of variance (ANOVA) and Tukey's post-hoc comparisons to determine if the frequency of fish visits and/or time spent foraging on invertebrates differed among treatments. To address whether removal of fish influenced herbivore densities (which were measured through time), we used a repeated measures ANOVA to test whether herbivore densities differentially increased or decreased through time on the different tile treatments.

Herbivory was quantified in each stream (except one due to missing data) as the log ratio $\ln$ [Chl.a1 TL tiles/Chl.a2TL tiles] where Chl.a is the amount of chlorophyll a (algal biomass) on tiles with algae only (1 TL) versus algae and herbivores (2 TL). We characterized the strength of trophic cascades in each stream as the log response ratio $\ln [P+/ P-]$ where $\mathrm{P}+$ and $\mathrm{P}-$ are algal biomass (measured as chlorophyll a) on experimental tiles in the presence verses absence of fish predators, respectively. Values of zero indicate no effect of predator exclusion on standing algal biomass. Values greater than zero signify that predator exclusions led to reduced algal biomass, as would be expected if predators have a positive, indirect effect on algae through their reduction of herbivores. Negative values, which occurred in a few streams, indicate that exclusion of predators exacerbated losses of algae to herbivores. To assess whether trophic cascades were significantly different than zero across all streams, we ran a mixed model ANOVA and tested for a non-zero intercept with stream included as a random effect in the analysis. Note that our use of $\log$ response ratios analyzed with a mixed model is identical to how meta-analyses routinely compare consumer effect sizes across systems (Leroux and Loreau 2008, Shurin et al. 2002). As such, we are essentially performing a meta-analysis of 17 experiments where each stream contributes one data point (i.e. effect size).

Lastly, we used linear regressions to assess whether the strength of trophic cascades covaried with the proportion of mobile or structurally defended herbivores, the number of algal and herbivore species, and the biomass specific rates of production (algal production-per-unit biomass (P:B)) within a stream. To determine the proportion of mobile or structurally defended herbivores, we used classifications from the literature to categorize herbivores according to their mobility and presence/absence of a structural defense (shell or casing) (see Appendix 1 Table A1 for classifications and references). These traits are known to play a key role in the ability of herbivores to avoid localized predation by fishes in streams and represent potential forms of predator avoidance (Lima 1998, Schmitz et al. 2004). Based on these traits, we calculated the proportional abundance of mobile and structurally defended herbivores present in each stream (Appendix 1 Table A1).

\section{Results}

\section{Effectiveness of exclusions}

Visual surveys showed that the electrical fences were highly effective in excluding fish from foraging on the treatment tiles. Although the number of times that predatory fish visited a tile over the 4-h observation periods did not differ among treatments (Fig. 3A; ANOVA, $\mathrm{F}_{2,311}=0.109, \mathrm{p}=0.90$ ), fish remained to forage on invertebrates for 14 to 16 times longer on control tiles $(6.1 \mathrm{~s} \pm \mathrm{SD} 0.33)$ than on the tiles with high $(0.38 s \pm$ SD 0.03$)$ or low $(0.44 s \pm$ SD 0.03$)$ voltage electrical exclusions (Fig. 3B; ANOVA, $\mathrm{F}_{2,311}=343.6, \mathrm{p}<0.01$; Tukey's: control vs low voltage, $\mathrm{p}<0.01$; control vs high voltage, $p<0.01$; high vs low voltage, $p=0.97$ ). The electrical fences with higher voltages were also effective in excluding invertebrate herbivores from the treatment tiles. Over the course of the experiment, herbivore densities remained 4.7 to 7.8 times lower on high voltage ( $4.7 \pm$ SD 1.5 ) or control tiles with no electrical current (7.8 \pm SD 2.1) compared to low voltage tiles from which predatory fish were excluded (36.7 \pm SD 6.8) (Fig. 3C; repeated measures ANOVA, $\mathrm{F}_{2,48}=7.7, \mathrm{p}<0.01$ ). Thus, the low voltage treatments successfully excluded fish, leading to significant increases in herbivore densities, whereas the high voltage treatments successfully excluded both fish and invertebrate herbivores from the colonization substrates.

\section{Variation in the strength of trophic cascades}

Results of a mixed model ANOVA indicated that log ratios of algal biomass were, on average, significantly greater than zero $(\mathrm{DF}=16, \mathrm{t}=2.72, \mathrm{p}=0.02)$ with a mean value of 0.34 and a $95 \%$ confidence interval from 0.07 to 0.60 

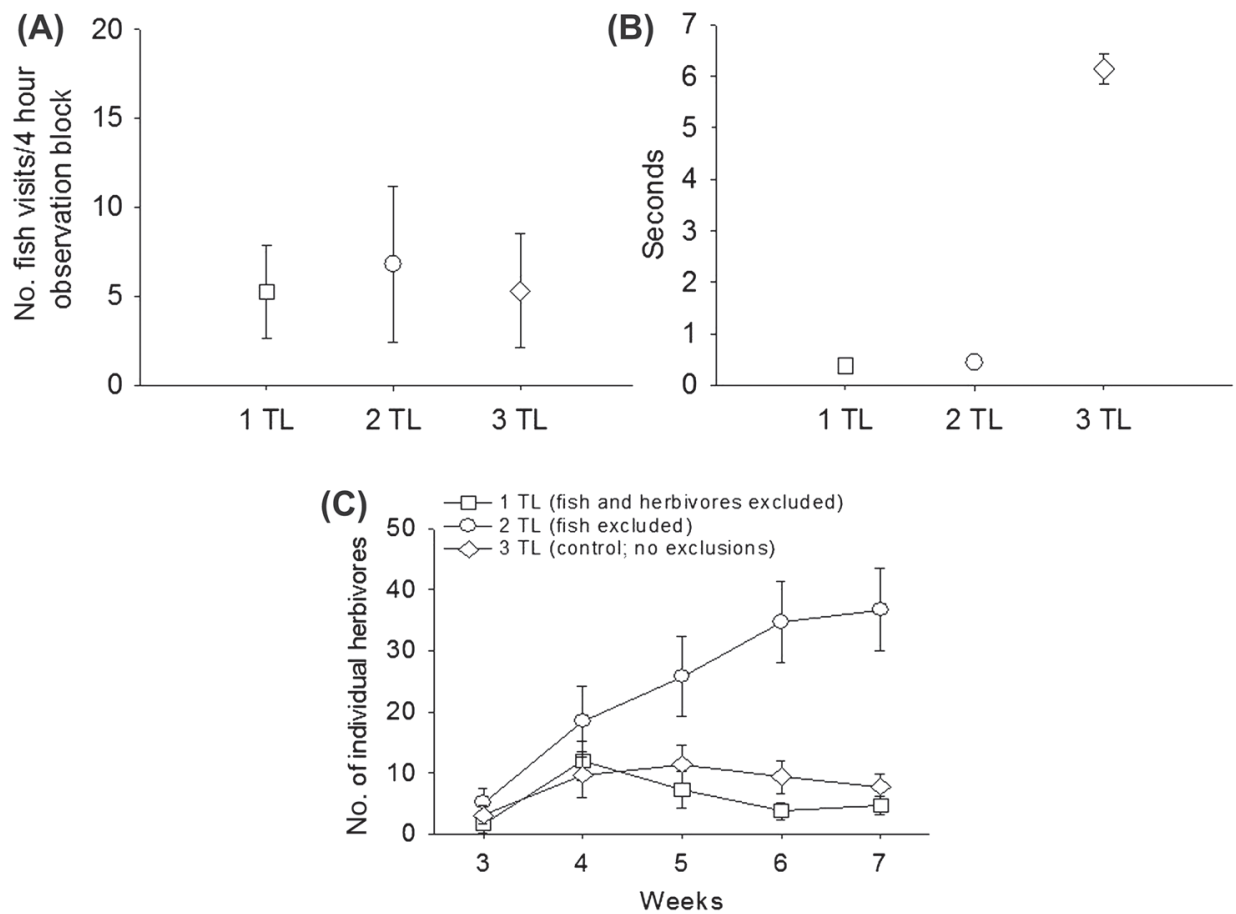

Figure 3. Electrical fences successfully prevented invertebrate herbivores and predatory fish from colonizing and/or foraging on experimental tiles placed in streams, thereby creating tile communities with only algae (1 trophic level or TL) or only invertebrate herbivores and algae (2 TL). Fish, invertebrates, and algae (3 TL) had access to control tiles. (A) Fish densities, as measured by the mean number ( \pm SD) of fish visits to each 4-h observation block, were not different between treatments and control tiles, however, (B) the mean ( \pm SD) number of seconds a fish spent foraging on a tile was significantly greater for the control tiles over those which were electrified to exclude fish. (C) The mean number $( \pm S D)$ of individual herbivores counted at weekly intervals from weeks three through seven were significantly higher at week seven on the tiles that excluded fish than on the control tiles where fish continued depredating herbivores.

(Fig. 4A). Thus, trophic cascades were prominent in the 17 streams studied with evidence of significant indirect effects of predators on primary producers. On average, fish predation on the control tiles increased algal biomass by $60 \%$ relative to tiles on which fish were excluded $\left(0.8 \mathrm{mg} \mathrm{l}^{-1} \pm \mathrm{SD}\right.$ 0.8 vs $0.5 \mathrm{mg} \mathrm{l}^{-1} \pm \mathrm{SD} 0.3$, respectively), and algal biomass in the absence of fish and herbivores increased by $140 \%$ relative to tiles on which herbivores grazed in the absence of predation $\left(1.2 \mathrm{mg} \mathrm{l}^{-1} \pm \mathrm{SD} 1.0\right.$ vs $0.5 \mathrm{mg} \mathrm{l}^{-1} \pm \mathrm{SD} 0.3$, respectively) (Fig. 4B; ANOVA, $\mathrm{F}_{2,46}=4.5, \mathrm{p}=0.02$ ).

Note, however, that there was considerable variation in both the direction and magnitude of predator impacts in the 17 streams (Fig. $4 \mathrm{~A})$. The values of $\ln [P+/ P-]$ across the 17 streams ranged from a low of -0.40 (predators decreased producer biomass by a factor of $0.67 \times$ relative to controls) to a high of +1.47 (predators increased producer biomass by a factor of $4.35 \times$ ). Thus, there was a substantial amount of variation in the indirect effects of predators on algae which provided ample opportunity to test for factors that co-varied with the magnitude of predator effects.

\section{Covariates of trophic cascades}

We found no relationship between the direction and strength of indirect predator effects and the proportion of mobile or defended grazers within a stream (trophic cascade strength $=0.14+0.37 \times$ herbivore mobility; $F_{1,15}=0.61$, $\left.\mathrm{p}=0.45, \quad \mathrm{r}^{2}=0.04\right) \quad$ (Fig. 5A) and trophic cascade strength $=0.40-0.93 \times$ herbivore defense; $\mathrm{F}_{1,15}=1.23$, $\left.\mathrm{p}=0.29, \mathrm{r}^{2}=0.08\right)$ (Fig. 5B). There was also no relationship between indirect predator effects and the total number of herbivores in the stream (trophic cascade strength $=0.36-$ $0.00009 \times$ number of herbivores; $F_{1,15}=0.04, p=0.84$, $\left.\mathrm{r}^{2}=0.003\right)$ or number of herbivores present on tiles where invertebrates were allowed to colonize (trophic cascade strength $=0.27+0.001 \times$ number of herbivores on $2 \mathrm{TL}$ tiles; $\left.\mathrm{F}_{1,15}=0.16, \mathrm{p}=0.69, \mathrm{r}^{2}=0.01\right)$. Furthermore, there was no relationship between herbivore diversity and the strength of indirect predator effects across streams (trophic cascade strength $=0.51-0.02 \times$ herbivore diversity; $F_{1,15}=0.17$, $\mathrm{p}=0.68, \mathrm{r}^{2}=0.01$ ) (Fig. 5C). Thus, we found no evidence to suggest that trophic cascades were associated with any measured aspect of herbivore mobility, defense, density or diversity.

Indirect predator effects were negatively related to algal species diversity, decreasing by $\sim 2 \%$ for each additional algal species identified from a stream (trophic cascade strength $=1.34 \quad-0.02 \times$ algal diversity; $F_{1,15}=4.20$, $p=0.058, r^{2}=0.23$; Fig. 5D). We also found that the strength of indirect predator effects was negatively related to biomass specific rates of production (P:B ratios) by algal communities across streams (trophic cascade strength $=0.67$ $-23.79 \times \mathrm{P}: \mathrm{B} ; \mathrm{F}_{1,14}=13.40, \mathrm{p}=0.003, \mathrm{r}^{2}=0.49$ ) (Fig. $5 \mathrm{E})$. However, we also noted that algal P:B and diversity exhibited a moderately strong correlation with one another (algal P:B $=-0.02+0.0006 \times$ algal diversity; $\mathrm{F}_{1,14}=4.47$, $\left.\mathrm{p}=0.05, \mathrm{r}^{2}=0.24\right)$. Given this, we conducted a partial regression analysis to determine the relationship of each factor to strength of indirect predator effects after holding the other factor statistically constant. The partial regression 

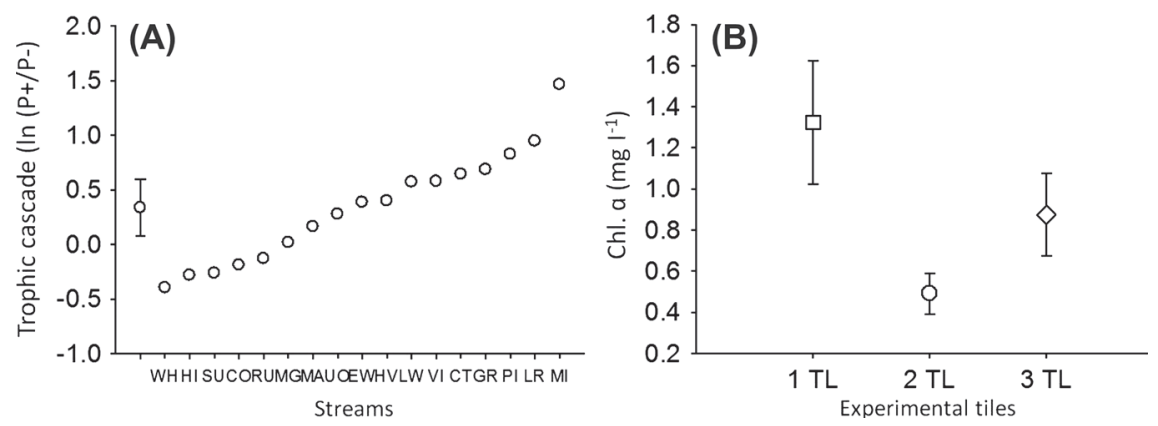

Figure 4. (A) The presence of a trophic cascade within each stream was measured as the log ratio of algal biomass (chlorophyll a) present on tiles with $(\mathrm{P}+)$ and without $(\mathrm{P}-)$ predators (In $[P+/ P-])$. The first value in the graph represents the mean $\pm 95 \%$ CI of the log ratio measured in all 17 streams as determined by a mixed model ANOVA that accounted for stream as a random variable. The value of the log ratio is then shown for each individual stream, ranked from lowest to highest (left to right). (B) Algal biomass measured as mean amount of chlorophyll a $( \pm S D)$ on tiles differed between treatments $(1 \mathrm{TL}=$ algae only; $2 \mathrm{TL}=$ algae and invertebrate herbivores; $3 \mathrm{TL}=$ algae, invertebrate herbivores, and fish) indicating that trophic cascades were contributing to the overall structuring of algal communities in streams.

analyses demonstrated that algal P:B could explain variation in strength of indirect predator effects after holding algal diversity constant, but algal diversity could not explain variation after accounting for algal $\mathrm{P}: \mathrm{B}$ ratios (algal diversity residuals $=0.24-16.34 \times$ algal $\mathrm{P}: \mathrm{B} ; \mathrm{F}_{1,14}=5.40, \mathrm{p}=0.04$, $\mathrm{r}^{2}=0.28$, and algal $\mathrm{P}: \mathrm{B}$ residuals $=0.16-0.003 \times$ algal diversity; $\left.\mathrm{F}_{1,14}=0.14, \mathrm{p}=0.72, \mathrm{r}^{2}=0.01\right)$. Furthermore, algal $\mathrm{P}: \mathrm{B}$ was inversely related to the total amount of herbivory on the tiles (herbivory $=1.21-24.58 \times$ algal $\mathrm{P}: \mathrm{B}$, $\mathrm{F}_{1,14}=14.57, \mathrm{p}=0.002, \mathrm{r}^{2}=0.51$ ), which helps explain why $\mathrm{P}: \mathrm{B}$ was the only factor significantly correlated with variation in the strength of indirect predator effects across streams.
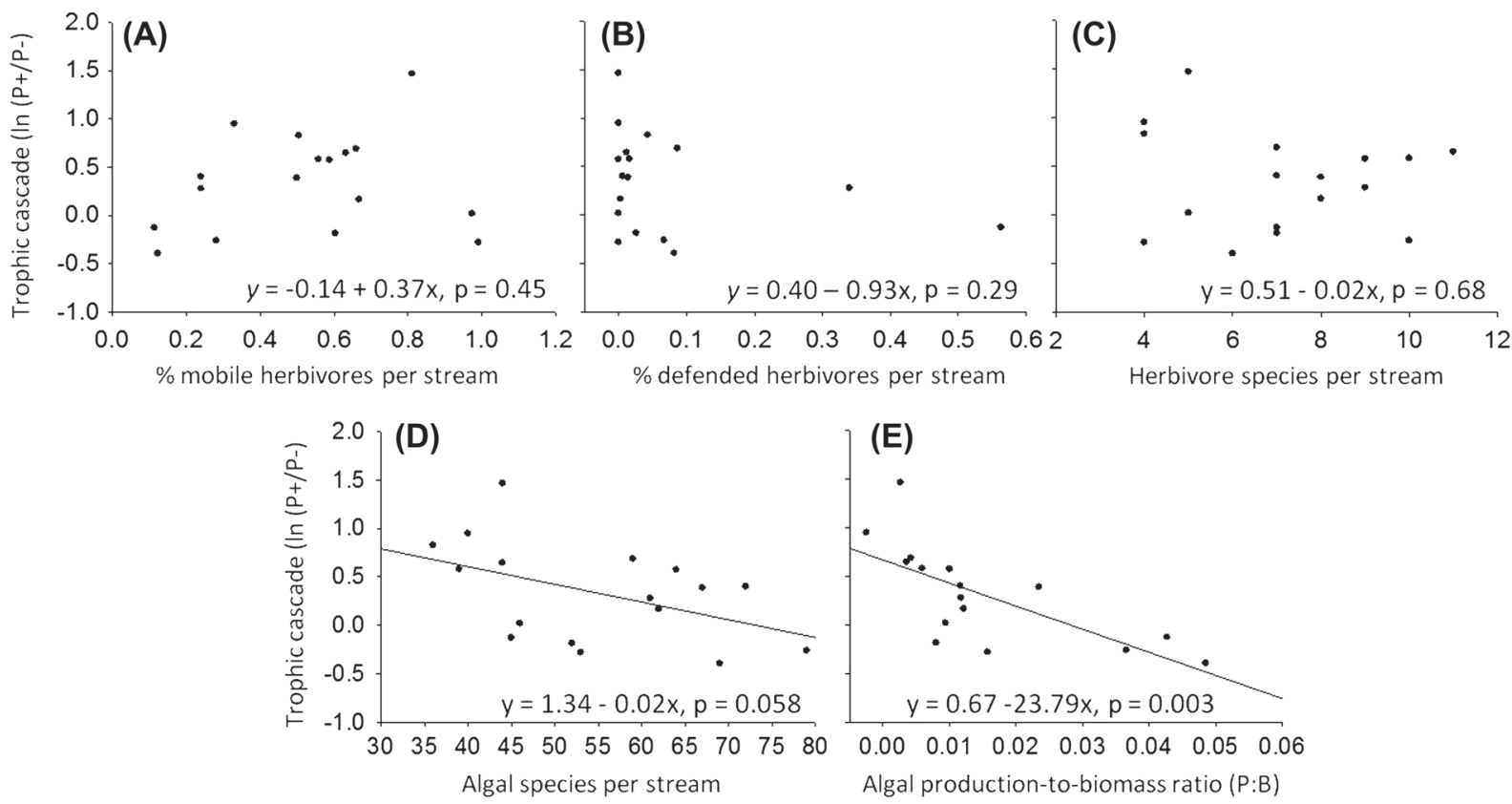

Figure 5. The presence of a trophic cascade within each stream was measured as the log ratio of algal biomass (measured as chlorophyll a) present on tiles with $(\mathrm{P}+)$ and without $(\mathrm{P}-)$ predators (In $[\mathrm{P}+/ \mathrm{P}-])$. The trophic cascade metric was not related to: (A) herbivore antipredator behavior as measured by the percentage of mobile herbivores present in each stream, (B) herbivore anti-predator defenses as measured by the percentage of herbivores defended by a hard casing or shell present in each stream, and (C) herbivore diversity across streams. The presence and strength of trophic cascades decreased with (D) increasing algal species diversity in streams, and E) increasing algal production-to-biomass ratios (P:B). Algal P:B and diversity were strongly correlated and subsequent partial regression analysis demonstrated that algal diversity was unrelated to trophic cascade strength.
Here we have reported the results of an experiment conducted currently across 17 streams throughout the Sierra Nevada mountain range. We have shown that, when averaged across all streams, top consumers indirectly increase the biomass of primary producers as would be predicted by a trophic cascade. However, the indirect effects of predators on algae ranged from moderately negative (predator removal increased loss of algae to herbivores) in a small number of streams, to strongly positive in others (predators increasing biomass $>4.35$-fold in the most extreme case). Within each stream, we collected the data needed to address three 
common predictions regarding potential controls over the strength of trophic cascades: 1) trophic cascades are weaker in systems where the dominant herbivores are able to avoid predation through increased mobility or defensive structures (Persson 1999, Schmitz et al. 2004), 2) trophic cascades are weaker in more diverse food webs (Strong 1992), and 3) the strength of trophic cascades increases as the producer production-to-biomass (P:B) ratios (turnover rates) increase (Shurin and Seabloom 2005). The results of our experiments did not fully support any of these predictions. We found no relationship between the indirect effect of predators and the proportion of herbivores that were considered to be highly mobile or defended by structures. We also found no relationship between indirect predator effects and the diversity of either herbivores or algae (after accounting for cross-correlations with other predictors). We did find a significant relationship between the strength of indirect effects by predators and the $P: B$ ratios of producers; however, this relationship was opposite of what has been theoretically predicted, a point that we return to later in the discussion.

Our results contrast with a recent meta-analysis by Schmitz et al. (2004) in which the authors synthesized results from studies that measured trophic cascades in marine, freshwater, and terrestrial systems. They hypothesized that a tradeoff between prey foraging efficiency and the risk of predation was a key factor driving variation in the strength of cascades across systems. The assumption behind their hypothesis is that mobile or defended herbivores can temporarily escape predation and then continue grazing, thereby dampening an indirect effect of predators on plant growth. We found that neither the abundance of highly mobile herbivores, nor the abundance of structurally defended herbivores was related to the strength of indirect predator effects. Of course, mobility and structural defense are just two of several means by which herbivores can resist or avoid predation (Schmitz et al. 2004, Trussel et al. 2006). Therefore, we cannot eliminate the possibility that other anti-predator behaviors or defenses not considered in our study played some role in influencing the results. But we can say that two of the more widely studied aspects of predation risk in streams played no role in driving variation in cascade strength in this study.

Although univariate analyses revealed no relationship between trophic cascade strength and the diversity of stream herbivores, we did initially find that the strength of indirect effects by predators decreased with increasing diversity of primary producers in a stream. At the same time, we found that algal diversity was strongly correlated with another covariate: algal $\mathrm{P}: \mathrm{B}$ ratios. After performing a partial regression analysis to statistically control for this correlation, there was no significant relationship between the strength of predator indirect effects and algal species richness. This lack of covariation adds to a body of literature that, as of yet, has produced little evidence of any relationship between trophic cascade strength and the diversity of food webs. Experimental studies that have explicitly manipulated species richness have found no effect of grazer diversity on trophic cascade strength (Duffy et al. 2005, Wojdak 2005). A recent meta-analysis by Borer et al. (2005) examined trophic cascades across a broad array of aquatic and terrestrial systems and concluded that species diversity at any level (plant, herbivore or predator) was unrelated to the strength of trophic cascades. The primary contrast to these conclusions comes from Halaj and Wise (2001) who examined the occurrence of trophic cascades in terrestrial systems and found they were most pronounced in homogeneous, simplified crop systems. They speculated that a lack of plant community diversity in the crop systems was a significant contributor to the prevalence of trophic cascades in these systems. It seems safe to say that, at present, existing data do not provide strong support for Strong's (1992) classic hypothesis that increasing food web diversity decreases the strength of trophic cascades. However, one caveat to this conclusion is that, while Strong's hypothesis was phrased in terms of species diversity, the specific characteristic of a diverse food web that was presumed to dampen cascade strength was the reticulate nature of species interactions that were thought to allow for many alternative pathways of energy flow in a diverse system. As such, a complete test of this hypothesis requires consideration of not just species diversity, but of the degree of connectedness among species, since it is possible for diverse food webs to be arranged into parallel chains composed of a small number of interacting species.

Of the potential covariates considered in our study, the strength of predator indirect effects on algal biomass was only significantly related to producer P:B ratios. Yet, the direction of this relationship was opposite of what is predicted in some food web models where high plant $\mathrm{P}: \mathrm{B}$ ratios generate stronger top-down control (Shurin and Seabloom 2005). The primary reason these models predict a positive relationship between P:B and trophic cascades is that, in systems with higher $\mathrm{P}: \mathrm{B}$ ratios, producers are assumed to allocate more resources to growth and photosynthetic tissue per unit biomass. Because these types of tissues tend to be more edible and nutritious for grazers (Cebrian 1999), it is assumed that higher P:B will support greater rates of herbivory, higher production of herbivores, and a greater abundance of predators that can exhibit top-down control.

Contrary to these predictions, we found that the magnitude of indirect predator effects on algae decreased with increasing P:B ratios. One of the primary reasons we obtained an inverse relationship between $\mathrm{P}: \mathrm{B}$ and the strength of trophic cascades is that, contrary to the assumption of past models, P:B and the magnitude of herbivory were inversely related across the 17 streams in our dataset. At present, we cannot say why this inverse relationship occurred. But one hypothesis that deserves further attention is that the most productive periphyton in these streams may have also been the least edible. Dominance by highly productive but inedible species may have dampened the strength of trophic cascades, as has been proposed by others (Borer et al. 2005, Chick et al. 2008).

This hypothesis runs counter to one of the key predictions of life-history theory where it is typically assumed that the ability of primary producers to resist or defend against herbivores is costly. As such, plants and algae are often expected to exhibit inherent tradeoffs between their ability to compete for resources and grow versus their ability to defend against consumers. But there is growing evidence that this tradeoff is not as common as has been assumed. For example, Viola et al. (2010) recently performed a meta-analysis of terrestrial plant competition and herbivory studies and found 
that less than one-third of all plant communities considered displayed any evidence of a tradeoff between a plant species' ability to compete for inorganic resources versus their ability to withstand consumption by herbivores. Similarly, a review of freshwater algae by Agrawal (1998) found that the results of many experiments are not consistent with lifehistory theory, such as when suppression of herbivores has led to dominance by grazing resistant algal taxa (a common result). If the most competitive or productive species are not constrained by their grazers to the extent that has been previously assumed, then one of the key theoretical assumptions about how P:B ratios influence trophic cascades could be fundamentally incorrect. To determine whether this is so, and to advance trophic cascade theory, future studies will need to determine how life-history traits of producers such as competitive ability, growth rate, and edibility or defense against herbivores covary with one another.

Acknowledgements - We thank the Cardinale Lab and J. Estes for discussion and comments that improved this manuscript; E. Padilla and R. Shulman for help in the field; A. Serrano and P. Pontau for laboratory help; and C. Nelson for assistance with statistics. This research was supported by National Science Foundation Grant DEB-0842009 (BC) and a Harvey Karp Post-Doctoral Research Fellowship (CK).

\section{References}

Agrawal, A. 1998. Algal defense, grazers, and their interactions in aquatic trophic cascades. - Acta Oecol. 19: 331-337.

Bernot, R. and Turner, A. 2001. Predator identity and trait-medited indirect effects in a littoral food web. - Oecologia 129: 139-146.

Blinn, D. and Herbst, D. B. 2003. Use of diatoms and soft algae as indicators of stream abiotic determinants in the Lahontan Basin, USA. - California State Water Resources Board.

Borer, E. et al. 2005. What determines the strength of a trophic cascade? - Ecology 86: 528-537.

Brett, M. and Goldman, C. 1996. A meta-analysis of the freshwater trophic cascade. - Proc. Natl Acad. Sci. 93: 7723-7726.

Cardinale, B. J. et al. 2002. The influence of substrate heterogeneity on biofilm metabolism in a stream ecosystem. - Ecology 83: 412-422.

Cardinale, B. J. et al. 2009. Does productivity drive diversity or vice versa? A test of the multivariate productivity-diversity hypothesis in streams. - Ecology 90: 1227-1241.

Carpenter, S. et al. 1985. Cascading trophic interactions and lake productivity. - BioScience 35: 634-639.

Cebrian, J. 1999. Patterns in the fate of production in plant communities. - Am. Nat. 154: 449-468.

Cebrian, J. and Duarte, C. 1994. The dependence of herbivory on growth rate in natural plant communities. - Funct. Ecol. 8: $518-525$.

Cebrian, J. et al. 2010. Producer nutritional quality controls ecosystem trophic structure. - PLoS One 4: e4929.

Chick, J. et al. 2008. Periphyton mat structure mediates trophic interactions in a subtropical marsh. - Wetlands (Syd.) 28: 378-389.

Cottingham, K. et al. 2005. Knowing when to draw the line: designing more informative ecological experiments. - Front. Ecol. Environ. 3: 145-152.

Cyr, H. and Pace, M. L. 1993. Magnitude and patterns of herbivory in aquatic and terrestrial systems. - Nature 361: 148-150.
Dalziel, C. and Massoglia, F. 1956. Let-go currents and voltages. - AIEE Trans. Power Apparatus Systems 75, part II: 49-56.

Duarte, C. and Cebrian, J. 1996. the fate of marine autotrophic production. - Limnol. Oceanogr. 41: 1758-1766.

Duffy, J. et al. 2005. Ecosystem consequences of diversity depend on food chain length in estuarine vegetation. - Ecol. Lett. 8: 301-309.

Duffy, J. et al. 2007. The functional role of biodiversity in ecosystems: incorporating trophic complexity. - Ecol. Lett. 10: 522-538.

Edwards, K. et al. 2010. Prey diversity is associated with weaker consumer effectsin a meta-analysis of benthic marine experiments. - Ecol. Lett. 13: 194-201.

Estes, J. and Palmisano, J. 1974. Sea otters: their role in structuring nearshore communities. - Science 185: 1058-1060.

Fraser, L. and Grime, J. 1998. Top-down control and its effectvon the biomass and composition of three grasses at high and low soil fertility in outdoor microcosms. - Oecologia 113: 239-246.

Gruner, D. 2004. Attenuation of top-down and bottom-up forces in a complex terrestrial community. - Ecology 85: 3010-3022.

Hairston, N. G. et al. 1960. Community structure, population control, and competition. - Am. Nat. 94: 421-425.

Halaj, J. and Wise, D. 2001. Terrestrial trophic cascades: how much do they trickle? - Am. Nat. 157: 262-281.

Herbst, D. and Blinn, D. 2007. Preliminary index of biological integrity (IBI) for periphyton in the Lahontan Region, eastern Sierra Nevada, California. - US Environmental Protection Agency.

Kurle, C. et al. 2008. Introduced rats indirectly change marine rocky intertidal communities from algae- to invertebrate-dominated. - Proc. Natl Acad. Sci. USA 105: 3800-3804.

Leroux, S. and Loreau, M. 2008. Subsidy hypothesis and strength of trophic cascades across ecosystems. - Ecol. Lett. 11: 1147-1156.

Lima, S. 1998. Nonlethal effects in the ecology of predator-prey interactions. - BioScience 48: 25-34.

McIntosh, A. and Townsend, C. 1996. Interactions between fish, grazing invertebrates and algae in a New Zealand stream; a trophic cascade mediated by fish-induced changes to grazer behaviour? - Oecologia 108: 174-181.

Mooney, K. et al. 2010. Evolutionary tradeoffs in plants mediate the strength of trophic cascades. - Science 327: 1642-1644.

O'Gorman, E. and Emmerson, M. 2009. Perturbations to trophic interactions and the stability of complex food webs. - Proc. Natl Acad. Sci. USA 106: 13393-13398.

O'Gorman, E. et al. 2008. Predator diversity enhances secondary production and decreases the likelihood of trophic cascades. - Oecologia 158: 557-567.

Opsahl, R. et al. 2003. Current velocity and invertebrate grazing regulate stream algae: results of in situ electrical exclusion. Hydrobiologia 499: 135-145.

Pace, M. L. et al. 1999. Trophic cascades revealed in diverse ecosystems. - Trends Ecol. Evol. 14: 483-488.

Paine, R. T. 1980. Food webs - linkage, interaction strength and community infrastructure - the 3rd Tansley Lecture. - J. Anim. Ecol. 49: 667-685.

Persson, L. 1999. Trophic cascades: abiding heterogeniety and the trophic level concept at the end of the road. - Oikos 85: 385-397.

Polis, G. A. 1999. Why are parts of the world green? Multiple factors control productivity and the distribution of biomass. - Oikos 86: 3-15.

Polis, G. A. and Strong, D. R. 1996. Food web complexity and community dynamics. - Am. Nat. 147: 813-846.

Polis, G. A. et al. 2000. When is a trophic cascade a trophic cascade? - Trends Ecol. Evol. 15: 473-475.

Power, M. E. 1990. Effects of fish in river food webs. - Science 250: 811-814. 
Power, M. E. 1992. Habitat heterogeneity and the functional significance of fish in river food webs. - Ecology 73: 1675-1688.

Power, M. E. 2000. What enables trophic cascades? Commentary on Polis et al. - Trends Ecol. Evol. 15: 443-444.

Power, M. E. et al. 2008. Seasonal reassembly of a river food web: floods, droughts and impacts of fish. - Ecol. Monogr. 78: 263-282.

Pringle, C. and Blake, G. 1994. Quantitative effects of Atyid shrimp (Decapoda: Atyidae) on the depositional environment in a tropical stream: use of electricity for experimental exclusion. - Can. J. Fish. Aquat. Sci. 51: 1443-1450.

Pringle, C. and Hamazaki, T. 1997. Effects of fishes on algal response to storms in a tropical stream. - Ecology 78: 2432-2442.

Schmitz, O. et al. 2000. Trophic cascades in terrestrial systems: a review of the effects of carnivore removals on plants. - Am. Nat. 155: 141-153.

Schmitz, O. et al. 2004. Trophic cascades: the primacy of traitmediated indirect interactions. - Ecol. Lett. 7: 153-163.

Shurin, J. and Seabloom, E. 2005. The strength of trophic cascades across ecosystems: predictions from allometry and energetics. - J. Anim. Ecol. 74: 1029-1038.

Shurin, J. et al. 2002. A cross-ecosystem comparison of the strength of trophic cascades. - Ecol. Lett. 5: 785-791.

Shurin, J. et al. 2006. All wet or dried up? Real differences between aquatic and terrestrial food webs. - Proc. R. Soc. B 273: $1-9$.
Steinman, A. and Lamberti, G. 1996. Biomass and pigments of benthis algae. - In: Hauer, F. and Lamberti, G. (eds), Methods in stream ecology. Academic Press, pp. 295-311.

Strong, D. R. 1992. Are trophic cascades all wet? Differentiation and donor control in speciose ecosystems. - Ecology 73: 747-754.

Tessier, A. and Woodruff, P. 2002. Cryptic trophic cascade along a gradient of lake size. - Ecology 83: 1263-1270.

Townsend, C. 2003. Individual, population, community, and ecosystem consequences of a fish invader in New Zealand streams. - Conserv. Biol. 17: 38-47.

Trussel, G. et al. 2006. The fear of being eaten reduces energy transfer in a simple food chain. - Ecology 87: 2979-2984.

Utermöhl, H. 1958. Zur Verollkommnung der quantitativen Phytoplankton-Methodik. - Mitt. Int. Ver. Theor. Angew. Limnol. 9: $1-38$.

Viola, D. et al. 2010. Competition-defense tradeoffs and the maintencance ofplant diversity. - Proc. Natl Acad. Sci. USA 107: $17217-17222$.

Wojdak, J. 2005. Relative strength of top-down, bottom-up, and consumer species richness effects on pond ecosystems. - Ecol. Monogr. 75: 489-504.

Wootton, J. and Power, M. E. 1993. Productivity, consumers, and the structure of a river food chain. - Proc. Natl Acad. Sci. USA 90: 1384-1387. 


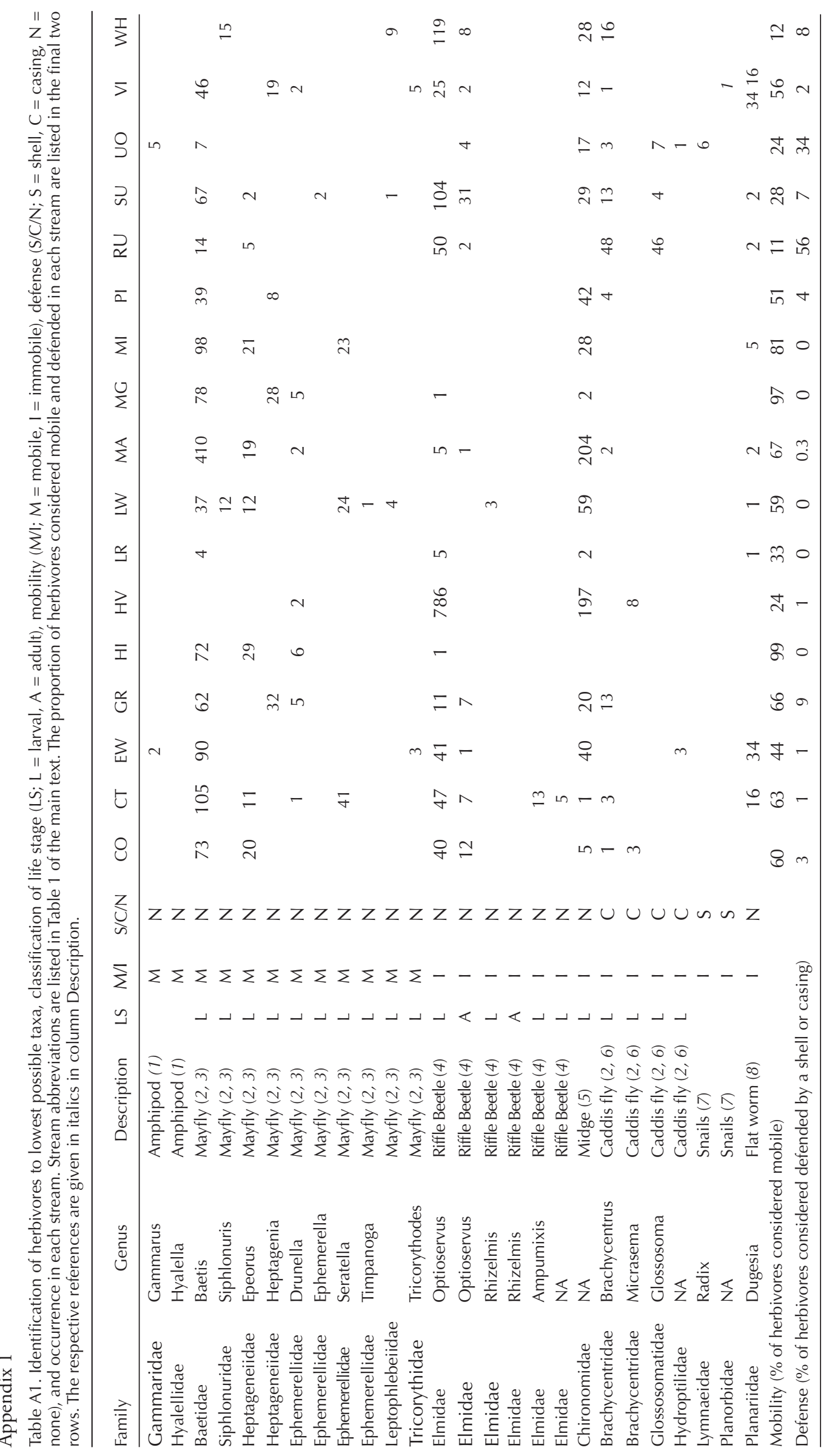




\section{References for Table A1}

Covich, A. and Thorp, J. 2001. Introduction to the subphylum crustacean. - In: Thorp, J. and Covich, A. (eds), Ecology and classification of North American freshwater invertebrates. Academic Press, pp. 777-810.

Poff, N. et al. 2003. Redundancy among stream grazers across a current velocity gradient. - Oecologia 134: 262-269.

Edmunds Jr., G. and Waltz, R. 1996. Ephemeroptera. - In: Merritt, R. W and Cummins, K. W. (eds), An introduction to the aquatic insects of North America. Kendall/Hunt Publishing Company, pp. 126-163.

White, D. and Brigham, W. 1996. Aquatic Coleoptera. - In: Merritt, R. W and Cummins, K. W. (eds), An introduction to the aquatic insects of North America. Kendall/Hunt Publishing Company, pp. 399-473.
Coffman, W. and Ferrington, L. C. 1996. Chironomidae. - In: Merritt, R. W and Cummins, K. W. (eds), An introduction to the aquatic insects of North America. Kendall/Hunt Publishing Company, pp. 635-754.

Wiggins, G. 1996. Trichoptera Families. - In: Merritt, R. W and Cummins, K. W. (eds), An introduction to the aquatic insects of North America. Kendall/Hunt Publishing Company, pp. 309-349.

Brown, K. 2001. Mollusca: Gastropoda. - In: Thorp, J. and Covich, A. (eds), Ecology and classification of North American freshwater invertebrates. Academic Press, pp. 297-329.

Kolasa, J. 2001. Flatworms: Turbellaria and nemertean. - In: Thorp, J. and Covich, A. (eds), Ecology and classification of North American freshwater invertebrates. Academic Press, pp. 155-180. 